Colles'-that is to say, the plane of fracture passes from in front downwards and backwards, and the lower fragment is displaced forwards. Some authors have misnamed this injury "chauffeur's fracture," but if it does occur as a result of starting a car it is only if the handle is released and swinging round strikes the back of the wrist. Reduction is not easy in these cases, and when it is completed the hand is best put up on a full cock-up splint. .It is a rare injury, and usually associated with considerable damage to the soft parts.

Fractures of the carpus are not very common, and are not infrequently overlooked in cases of so-called sprained wrist. If such a case fails to clear up in the usual time an X-ray examination will often show a fracture of one of the carpal bones.

By far the commonest carpal bone to be fractured is the scaphoid, though fractures of the other bones, especially of the proximal row, do occur. Fracture of the scaphoid results from a fall on the extended hand and is commoner in men than women. The fracture is usually transverse across the waist of the bone, and in some cases there is little or no displacement. Tenderness in the so-called "anatomist's snuff-box" and pain which is increased by dorsiflexion and radial flexion of the hand are typical, and there may be a localized swelling on the radial side of the wrist. If there is little or no displacement the hand should be put up on a cock-up splint, and if in cases with displacement the bone can be manipulated into position the same course should be followed.

The maintenance of dorsiflexion is most important, as if it is not maintained these patients readily develop a flexion deformity of the wrist with great disability.

If there is much displacement, and if, as usually happens, it cannot be removed, the bone must be excised surgically. While in such cases a perfect result cannot be guaranteed, I think it gives the patient the best chance.

A cock-up splint should be worn for ten to twelve days, and after that massage and movement can be begun. Although this fracture often looks a trivial injury in an X-ray plate, it is frequently responsible for much disability, and the patient must be persuaded to agree to vigorous treatment from the start.

\section{RIDDING THE EMPIRE OF LEPROSY.}

\section{A FAR-SPREAD CAMPAIGN.}

By a variety of methods the British Empire Leprosy Relief Association is working toward "the wonderful ideal," to use the phrase of its patron, H.R.H. the Prince of Wales, of eliminating leprosy from the British Empire within a generation. Statistical estimates give the number of sufferers from the scourge within the King's dominions as $4 \mathrm{I} 6,000$; but there are high authorities who hold this figure to be far below the mark. Dr. Muir, the Leprosy Research Worker at the School of Tropical Medicine, Calcutta, has stated that a carefully conducted but limited survey which has recently been made tends to show that there are in India alone between half a million and a million lepers. It is to be remembered that efforts to conceal the disease are widespread on the part of the sufferers and of their families, especially where the facilities for out-patient treatment provided by modern discoveries are little known.

The methods by which the Association seeks to fulfil the great mission for which it was founded in 1924 are indicated in the Annual Report for 1928, issued by the Association from 24 Cavendish Square, W.I, under the title of "Some Questions of Empire Suffering." Six questions are asked and answered. The first is "Who" are the people concerned, and it is shown in reply that there are lepers of all ages and 
conditions, for the most part outcast and destitute, but including some men and women of wealth and influence. The question "Where" the sufferers are to be found is answered. There are more lepers under the British flag than there are under any other political grouping.

In answer to the question "What" leprosy is, it is shown that it is not specially contagious, and the majority of lepers only develop the disease after prolonged contact with other sufferers. Leprosy is not hereditary, but little children are specially susceptible to contagion, and the majority of lepers contract the disease before they are twenty years of age. The question "Why" the campaign for eradication has been undertaken is answered by reference to the humanitarian, the patriotic and the Christian aspects of the task. The recent remark of Viscount Chelmsford, Chairman of the General Committee of the Association, that "the health of the peoples within the Empire comes first among the objects of good government," is quoted.

The question of most importance in this well illustrated report is that of "How" the problem is being dealt with. In the first place, the Association provides the latest curative treatments for the disease. Sir Leonard Rogers, the greatest authority in the British Empire on leprosy, writes that the outstanding features of the past year are the great number of lepers under treatment in our tropical African colonies, and the continued success of sodium hydnocarpate injections. Supplies of this injection are distributed widely to missionary and other organizations by the Association. No less an amount than would provide for 430,000 doses has been sent out to British Possessions, and for 76,600 doses to workers in other countries. Syringes and other medical supplies are also sent out.

Funds are provided for the enlargement of existing and the opening of new Treatment Centres. A list of grants for such purposes made during the year shows a total of $£ 3,947$. The Treatment Centres supported have the warm approval of the Chief Medical Officers in all the colonies and protectorates, and the Governments are themselves giving substantial grants of money for the extension of this type of work. In India supplies of the latest drugs and grants are provided by the Indian Council of the Association, which, at the instance of the Marquis of Reading when Viceroy, raised a fund amounting to over $€ \mathrm{r} 60,000$, for work within the Indian Empire.

The Association also does valuable service by providing the latest information on the subject of leprosy and its treatment by means of a quarterly publication entitled "Leprosy Notes"; by reprint of important articles on leprosy, and by the distribution of copies of "Leprosy" by Rogers and Muir, and other works. The Association sends out seeds of the trees from. which the oils used in the treatment of leprosy are obtained. Success in cultivation therefrom has been obtained in various parts of the Empire. A report from $\mathrm{Fiji}$, for instance, states that they have now nearly one thousand trees grown from the seed supplied by the Association. Branches of the Association have been formed in many of the colonies, and also in Great Britain, for the purpose of obtaining support for the work.

The final question of the series is "When ?" and the answer is "Now," the summary of reasons given being "The lepers are waiting; the curative remedies are available; suffering continues; lives are being wasted ; the lepers appeal for help." The Committee expresses the firm belief that if the plans which are now being advocated by the Association, and in many. parts of the Empire put into operation, can be pushed forward with real deteımination, there is a possibility of seeing the last of leprosy, at least in many parts of the Empire, within the next thirty years or so.

The Committee receives appeals for help from all parts of the Empire, and desires to 
meet every need that exists, but to this end additional support is necessary. The report is interspersed with extracts from letters from the widespread field in which the Association is forwarding the great campaign. A typical quotation is from a nurse in Northern Tanganyika, who writes: "The leper clinic up here is in its early stages, but it is very hopeful. We have patients attending from four different tribes, and it is the first time up here in this very primitive isolated hill district that any one has come forward for treatment acknowledging himself a leper. It is great to see the hope in their faces now, because they have simply been living hidden away in the past. There are many more to come forward still." The Association provided funds for the building of a small dispensary at this Treatment Centre, and some fifty lepers are being regularly treated.

\section{SURGICAL RESURRECTIONS-III.}

\author{
(Continued from p. ro5.)
}

\section{AsPhyXia By Thyroid TUMOUR WHEN LOCAL ANESTHETIC INFILTRATION WAS ADDED.}

SoME years ago I was asked to operate upon a woman, aged 6o, who was troubled with a fair-sized adenoma of the thyroid. The practitioner who referred the case to me stated that a consulting physician who had seen the patient advised that any operation should be performed under local anæsthesia, for there were symptoms of thyroid poisoning which in his opinion contraindicated general anæsthesia. There was certainly considerable exophthalmos, but the other symptoms of exophthalmic goitre were almost absent, and the diagnosis was certainly that of a toxic adenoma of the gland chiefly affecting the right lobe and contiguous part of the isthmus.
At that time I was little practised in the technique of local anæsthesia for thyroid operations, and thought it fairer to hand the case over to a surgical friend who had had a large experience of local anæsthesia. The patient was accommodated in a private ward some little distance from the theatre, and the decision was made to inject the local anæsthetic before taking her to the operating room. No difficulty was experienced in performing the local infiltration, but when this had been three parts done the patient began to look slightly uncomfortable and complained of difficulty in getting her breath. Discomfort soon became obvious and distress and slight cyanosis developed. Very rapidly the symptoms of asphyxia began to appear and she became unconscious. Seeing that prompt action would need to be taken, I ran to the theatre to warn them to have everything absolutely ready and to bring back a few instruments. I was soon followed by the surgeon himself, who with obvious agitation said that unless something were done at once the patient was lost. He snatched up a scalpel and two or three artery-clips and we both sped back to the bedroom. As we opened the door we were met by the Sister in charge who said that the patient was dead. The porters had lifted her from the bed to the stretcher intending to hurry her to the theatre, but when all evidence of breathing had ceased and no pulse could be felt at the wrist the Sister had made them put the stretcher down on the floor. There was no sign of life apparent when we arrived though naturally no prolonged auscultation of the heart was carried out. I went down on my knees and began to perform artificial respiration, whilst my friend with a celerity which was amazing (and which to this day I remember with envy), also knelt down and with two or three bold and skilful cuts with the knife exposed the thyroid gland and dislocated forward the right lobe which was causing the respiratory obstruction. The whole of this manœuvre only took a few. seconds, during which time I was continu- 